\title{
O FEMINISMO E SUAS VOZES OCULTADAS
}

\author{
FEMINISM AND ITS HIDDEN VOICES
}

\author{
Glenda Roberta Mendes de Lima ${ }^{1}$ \\ Meirilane Xavier da Silva ${ }^{2}$
}

\begin{abstract}
RESUMO: Essa pesquisa tem como objetivo geral identificar na literatura a história do movimento feminista e as histórias que, não foram contadas durante o movimento. $O$ objetivo específico desse estudo é analisar na literatura os desafios das mulheres negras no movimento feminista da época, pelo fato de não serem aceitas pelas feministas brancas de classe média alta. Foi aplicado um estudo de revisão bibliográfica nas bases de dados do livro: Pode o subalterno falar? (ALMEIDA, 2014). Feminismo, (JENAINATI E GROVES, 2020), O que é lugar de fala. (RIBEIRO, 2017). A pesquisa foi realizada no período de fevereiro de 202I. Utilizando- se os descritores e o cruzamento das palavras- chaves para facilitar a busca dos dados. A pesquisa passou por três etapas: I- leitura dos títulos, 2- leitura dos resumos dos textos, 3- leitura na íntegra. A análise de dados foi através de fichamento. $\mathrm{O}$ estudo identificou que o movimento feminista não atendia as necessidades das mulheres negras, assim, elas não tinham voz no movimento por não serem consideradas importantes para o movimento.
\end{abstract}

Palavras -chaves: Feminismo. Movimento. Vozes.

ABSTRACT: This research has the general objective of identifying in the literature the history of the feminist movement and the stories that were not told during the movement. The specific objective of this study is to analyze in the literature the challenges of black women within the feminist movement of the time, due to the fact that they are not accepted by white upper middle-class feminists. A bibliographic review study was applied to the book's databases: Can the subordinate speak? (ALMEIDA, 2014), Feminism, (JENAINATI

\footnotetext{
I Graduação em Ciências Sociais pela Universidade Federal de Rondônia (UNIR).

2 Graduação em Ciências Sociais pela Universidade Federal de Rondônia (UNIR). E-mail: lanaxavier455@gmail.com.
} 
e GROVES, 2020), What is a place of speech. (RIBEIRO, 2017). The research was carried out in the period of February 2021. Using the descriptors and the crossing of the keywords to facilitate the search for the data. The research went through three stages: $\mathrm{I}$ - reading the titles, 2- reading the abstracts of the texts, 3-reading in full. Data analysis was done through file. The study identified that the feminist movement did not meet the needs of black women, thus, they had no voice within the movement because they were not considered important to the movement.

Keywords: Feminism. Moviment. Voices.

\section{MOVIMENTO FEMINISTA}

O movimento feminista surge no século XIX, onde as mulheres se unem para acabar a opressão dos homens sobre elas.

Antes de surgir esse movimento, as mulheres não podiam votar, não tinham direito à educação e eram vistas apenas como um objeto de reprodução, não tinham direito de falar nem mesmo se tivesse vontade. O seu papel além de reproduzir era o de dona de casa: lavar, passar e cozinhar.

Mas com o surgimento do feminismo, as mulheres começaram uma espécie de destruição desse pensamento, onde em primeiro lugar, o direito à educação, o que possibilitou a ida das mulheres à escola dos homens. Podendo assim, assumirem cargos que apenas os homens ocupavam dentro de empresas e escolas.

Mas ainda faltava o direito ao voto, que também era uma das grandes questões que não dava voz as mulheres dentro da política.

Contudo, com a colaboração do feminismo, a mulher ganhou o direito a votar. $\mathrm{O}$ primeiro país foi a Nova Zelândia, onde no dia I9 de setembro de I893, o governador Lord Glasgow assinou uma nova lei eleitoral que tornou o país o primeiro no mundo em que as mulheres tinham o direito de votar nas eleições parlamentares, levando aos outros países a também permitirem o voto feminino, despertando o interesse dessas mulheres pela política, 
de modo que, o interesse não ficasse apenas nos votos eleitorais, mas também se interessassem por cargos políticos, como o que tem sido visto ao longo dos anos, por exemplo a ex-presidente Dilma Rousseff, em or de janeiro de 2011 no Brasil e Cristina Kirchner, em Io de dezembro de 2007 na Argentina.

Mesmo com o avanço no poder político, ainda encontramos muitas dificuldades com a abertura de vagas para mulheres que desejam concorrer à cargos políticos nas eleições. Os partidos políticos não apostam na candidatura feminina, como se pode ver nas eleições de 2020 no Brasil, onde as mulheres representavam apenas I2\% das candidaturas à prefeito no, segundo o Tribunal Superior Eleitoral.

\section{AS ONDAS DO FEMINISMO}

Com o passar do tempo, o feminismo foi se dividindo em etapas, o que fez com que o movimento perdesse um pouco a força.

\section{I A primeira onda do feminismo}

A primeira onda feminista era um movimento que atendia apenas mulheres brancas de classe média alta, ocorreu no século XIX e avançando pelo começo do século XX. Teve início no Reino Unido e nos Estados Unidos, com objetivo de ter a igualdade de direitos para homens e mulheres. As mulheres se organizaram e protestaram contra as diferenças contratuais, a diferença na capacidade de conquistar propriedades contra casamentos arranjados que ignoravam os direitos de escolha e os sentimentos das mulheres.

No final do século XIX, a primeira onda feminista ficou mais ativista e passou a contestar de forma significativa a questão do poder político. Como foi falado no começo do artigo, as mulheres até então, eram proibidas de votar e eleger seus representantes. A princípio foi muito difícil, por ser algo que rompia com os padrões históricos das sociedades. Os resultados começaram a aparecer no século XX de forma gradual. O voto foi permitido às mulheres a partir de I9I8, no Reino Unido. Mas, mesmo assim, só tinham direito ao voto 
mulheres com mais de 30 anos. Já nos Estados Unidos da América, a conquista ao voto só aconteceu no ano de 1919.

\subsection{A segunda onda feminista}

A segunda onda feminista é uma continuidade da primeira onda feminista, com as mulheres se organizando e reivindicando seus direitos. Porém há características que distinguem as duas fases. Na primeira fase, as mulheres lutavam por conquistas de direitos políticos, na segunda fase as feministas estavam preocupadas especialmente com o fim da discriminação e a competição entre sexos.

A segunda onda teve seu início no começo da década de 60 , onde as mulheres ganharam espaço mais uma vez e conseguiram ser ouvidas pela sociedade. Esse segundo movimento durou até a década de 8 o e foi denominada "O pessoal é político", que foi criado pela feminista Carol Hansch. A nova fase identificou o problema da desigualdade como a união de problemas culturais e política, fazendo com que as mulheres fossem politizadas e combatessem as estruturas sexistas de poderes.

No ano de 1964 que surgiu a frase "Liberdade das mulheres" falada nos Estados Unidos e foi fundamental para o movimento. Como a primeira onda feminista critica os contratos matrimoniais que não incluíam os interesses e sentimentos das mulheres, a segunda onda passou a criticar a ideia de que as mulheres tinham que cuidar dos filhos e do lar. Essa ideia inovou o cenário social dos Estados Unidos, que foi invadido por mulheres que queriam trabalhar, sustentar-se e serem respeitadas como os homens eram dentro da sociedade.

Como as atitudes das mulheres variam de acordo com raça, classe, idade e nível de instrução, as feministas da segunda onda, onde existe questionar uma experiência feminina universal. 
As exigências, em meados do século $\mathrm{XX}$, no movimento de libertação da mulher tinha objetivos claros e fazia campanha para conquistar seus locais de fala. As mulheres são pessoas? E mal acredito que qualquer pessoa de nossos adversários tenham a audácia de dizer que não.

\subsection{Terceira onda feminista}

Vem para corrigir as falhas e as lacunas deixadas pela fase do movimento que veio antes, que apenas das definições da feminilidade que se apoiavam especialmente nas experiências vividas por mulheres brancas de classe alta da sociedade, esquecendo das mulheres negras como cita Djalma Ribeiro em seu livro “O que é lugar de fala?”, onde ela cita o feminismo hegemônico, em que as mulheres negras, ao ocuparem um lugar de fala dentro do movimento, possuem um ponto de vista especial enxergarem a sociedade através de um aspecto mais amplo, o que proporciona uma potência crítica.

A terceira onda feminista buscava o que era bom para cada mulher, seja ela brancas ou não-brancas. As mulheres negras ganharam voz, puderam também expressar seus desejos, como se queriam se casar ou não, se queriam ter relações com homens ou não.

Isso aconteceu quando o feminismo abdicou da estrutura universal ao se falar de mulher e levar em conta as outras interseções como raça, orientação sexual, identidade de gênero, e tudo isso foi falado mais fortemente na terceira onda de feminismo sendo Butler um dos grandes nomes.

Porém, isso vem sendo falado muito antes com a atuação de feministas negras, como Truth e entre outras na primeira onda do feminismo. $\mathrm{Na}$ segunda onda feminista, o problema é a falta de visibilidade do movimento.

O valor mais elevado e o compromisso da mulher é a realização da própria feminilidade. A raiz dos problemas das mulheres no passado é que elas invejaram os homens 
ao invés de aceitarem sua própria natureza, que só encontra realização na passividade sexual, na dominação masculina e no amor.

As feministas encontraram uma estrutura social em que podiam interagir e comparar as preocupações em comum com outras origens. As integrantes dos grupos de mulheres eram educadas sobre a política de discriminação e a concepção que tinham em relação à sociedade.

O feminismo é um movimento que busca a dependência feminina, porém, como foi mostrado ao longo do artigo, não atendia a todas as mulheres. $\mathrm{O}$ que ocasionou sua divisão em fase, que fez com que o movimento perdesse um pouco de suas forças e fez com que até hoje não funcionar como deveria.

\section{PODE O SUBALTERNO FALAR?}

Um dos questionamentos baseado em crítica na autonomia, era sujeito subalterno como premissa, remete a preocupação de Spivak em teorizar um sujeito sobre o subalterno que não pode ocupar uma categoria monolítica e indiferenciada, pois o sujeito é irredutível heterogêneo. Sendo assim, o argumento problematizado pela desconstrução derridiana, a autora rejeita algo que ainda ela considera errônea, a apropriação do termo subalterno que não pode ser usado para referir a todo e qualquer sujeito marginalizado, um termo resgatado significa que lhe atribui, se referindo ao proletariado, ou seja, a voz não pode ser ouvida. Spivak revela o lugar incômodo e a cumplicidade do intelectual que julga poder falar pelo outro, ainda assim aumenta e reproduz as estruturas de poder e opressão, mantendo o subalterno no silenciado sem lhe oferecer uma posição ou espaço de onde possa falar, no qual possa ser ouvida, alerta também para constituir o outro e o subalterno como objeto de conhecimento que meramente fala pelo outro.

As expressões que acaba de ser expressadas são validas apenas se estiverem falando da consciência da mulher subalterno ou mais aceitável, ainda assim, participar do trabalho antissexista entre as mulheres de cor ou as mulheres sob opressão de classes no primeiro e 
no terceiro mundo, algumas informações em áreas estão silenciadas como na antropologia, na ciência política, na história e na sociologia, as pressuposições e as construções de uma consciência ou de sujeito imperialista, mesclando a violência epistêmica como avanço do conhecimento e da civilização. E a mulher subalterna continuará tão muda como sempre esteve, em um campo carregado de perguntas, perguntar sobre consciência da mulher subalterna. Spivak relata que muitas mulheres foram obrigadas a entender o projeto feminista, como Culler o descreve assim agitando a opinião pública, algumas são opiniões acadêmicas nos Estados Unidos, em questão do individualismo entre mulheres e homens com situações de ascensão social, algum apelo muitas vezes se dá por crítica ao positivismo, com alguns problemas por meio de sentença, por esta analogia entre vitimização ideológica do intelectual pós-colonial, as mulheres são vistas como bode expiatório um desejo inicial em dar a voz histérica de transformar a ideologia masculina imperialista.

\section{BIBLIOGRAFIA}

ALMEIDA, Sandra Regina Goulart; FEITOSA, Marcos Pereira e FEITOSA, André Pereira. Pode o Subalterno Falar? Belo Horizonte: UFGM, 2014.

JENAINATI, Cathia e GROVES, Judy. Feminismo: Um Guia Gráfico. Rio de Janeiro: Sextante, 2020.

RIBEIRO, Djamila. O Que é Lugar de Fala? Belo Horizonte: Letramento, 2017. 